\title{
Analysis on the influence of runoff trend in the Liusha River Basin of Xishuangbanna
}

\author{
Ling zhen ${ }^{1,2}$, Xu shan ${ }^{1, *}$, Dong minghua ${ }^{1}$, Feng guojian ${ }^{1}$, Huo hong ${ }^{1}$, Chen fan $^{1}$, Peng yan ${ }^{2}$ \\ ${ }^{1}$ Kunming University, Kunming, 650214; \\ ${ }^{2}$ College of Tourism and Geographic Sciences, Yunnan Normal University, Kunming, 650050
}

\begin{abstract}
In recent decades, there are lots of the changes of land use in the Liusha River basin in Xishuangbanna, Yunnan Province. The large-scale replacement of natural forests by rubber plantation have had a certain impact on the ecological environment and water resources in the Liusha River basin. Based on the data of runoff, rainfall and evaporation from 1963 to 2015 measured by Menghai Hydrological Station of Liusha River, the effects of climate change and human activities on the ecological environment of Liusha River runoff and the degree of change were analyzed by using the comparison method of slope change rate of runoff accumulation. The research results show that the cumulative amount of runoff flow after mutation presents significant decrease trend from 1963 to 2015. Because of the Liusha river runoff change decision which residents downstream watershed water security, the runoff of the ecological environment situation and analysis, the protection of natural resources such as forests and the effective protection of regional water resources sustainable development has important guiding significance.
\end{abstract}

\section{Introduction}

Liusha River is not only an important tributary of the lower reaches of Lancang River in Yunnan Province, but also the nearest river to the center of Jinghong City in Xishuangbanna. Since the mid-1990s, the population boom and the huge demand for rubber in the global market have led to the deforestation of a large number of primary forests due to the massive planting and cutting of rubber and tea trees in the upstream basin of the Liusha River ${ }^{[1]}$.Ecological environment, biological diversity and regional water security caused a certain influence by large, single economic forest plantations on the whole river basin. ${ }^{[2-3]}$ The new trend of runoff change shows regularity. The periodic change and development situation of Liusha river runoff and quantitative calculation had been analyzed. It is important to contribute effective management and reasonable development of the basin water resources to figure out the impact of climate change and human activities on the runoff trend.

\section{Study site}

Liusha River $\left(100^{\circ} 5^{\prime} \sim 100^{\circ} 35^{\prime} \mathrm{E}, 21^{\circ} 40^{\prime} \sim 22^{\circ} 06^{\prime} \mathrm{N}\right)$ in Xishuangbanna,Yunnan province, the basin area is about $2067 \mathrm{~km}^{2}$. It is typical of yunnan province are greatly influenced by human activity environment of the basin. The annual average temperature $21.8^{\circ} \mathrm{C}$, annual average rainfall of $1492.9 \mathrm{~mm}, 80 \%$ of which are mainly distributed in the rainy season. The elevation difference in the basin fluctuates greatly, with the highest elevation being $2400 \mathrm{~m}$ and the lowest elevation being $499 \mathrm{~m}$. The distribution ofLiusha River basin and main runoff control stations in Xishuangbanna is shown in Figure 1. 


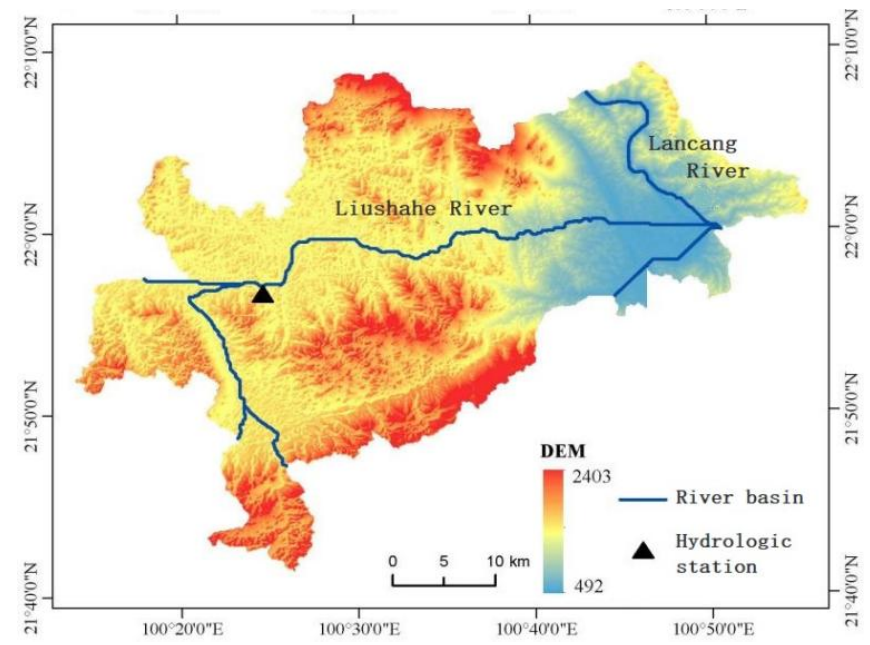

Fig.1 DEM of Liusha River basin and main control stations in xishuangbanna

Based on multiple remote sensing data such as Landsat and MOIDS, the distribution of land use in theLiusha River basin from 1990 to 2015 was analyzed (As shown in Figure 2). The natural forest area in the

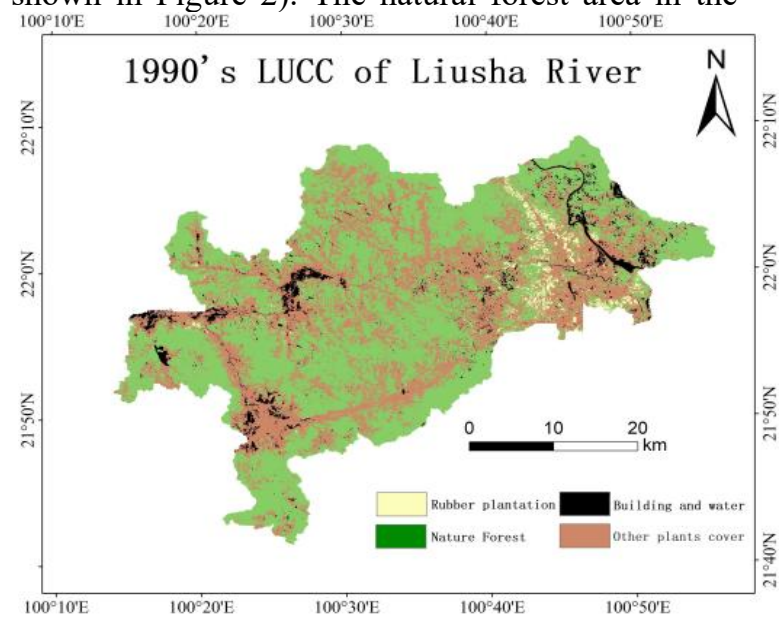

Liusha River basin was further reduced from $990 \mathrm{~km}^{2}$ in 1990 to $506 \mathrm{~km}^{2}$ in 2015 , with a decrease of $48.9 \%$, and the rubber forest area increased from $29 \mathrm{~km}^{2}$ to $270 \mathrm{~km}^{2}$, with an increase of $89.3 \%$.

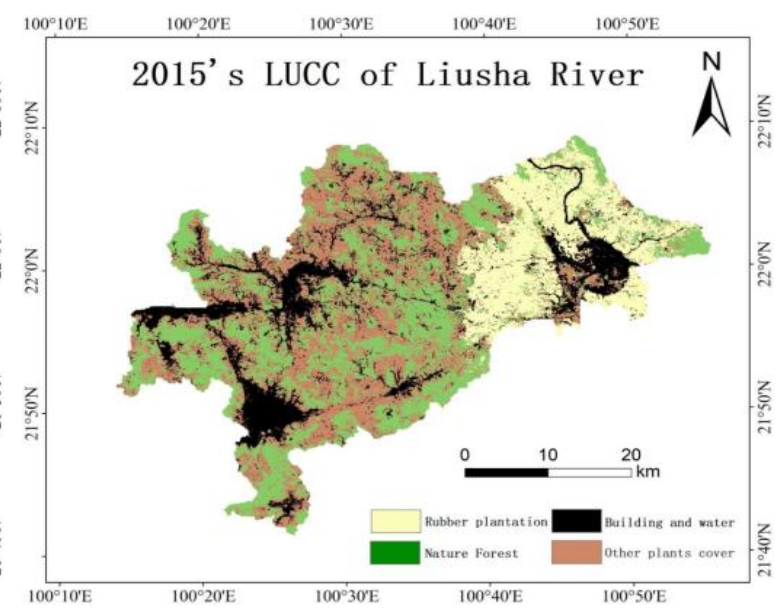

Fig.2 Liusha River basin land use change distribution map

\section{Methods}

Based on Liusha river menghai hydrological station of the rainfall and evaporation impact runoff and contribution can be cumulant slope rate of change in comparison method ${ }^{[4-5]}$. It can be calculated the contribution rate of human activities on runoff change and then use the cumulative departure method ${ }^{[5-6]}$ to judge the elements evaporation sequences change turning point. Then concluded the development trend.

Menghai Hydrological Station (the main control basin area is $1032 \mathrm{~km}^{2}$ ) for xishuangbannaLiusha River basin control station, evaporation, runoff, rainfall (evaporation related data are determined by Kendall E601 evaporator), the basic situation of data collection station is shown in Table 1.

Table 1 Hydrological and Meteorological Data Collection Stations

\begin{tabular}{|c|c|c|c|c|c|c|c|}
\hline Basin & River & Station & $\begin{array}{c}\text { Elevation } \\
(\mathrm{m})\end{array}$ & $\begin{array}{c}\text { Control area } \\
\left(\mathrm{km}^{2}\right)\end{array}$ & \multicolumn{2}{|c|}{ Data Information } \\
\cline { 5 - 7 } & & & & precipitation & \multicolumn{2}{|c|}{ runoff } & evaporation \\
\hline $\begin{array}{c}\text { Lancang } \\
\text { River }\end{array}$ & $\begin{array}{c}\text { Liu Sha } \\
\text { River }\end{array}$ & MengHai & 1168 & 1032 & $1958-2015$ & $1958-2015$ & $1963-2010$ \\
\hline
\end{tabular}




\section{Results and discussion}

\subsection{Runoff Trend analysis}

In this paper, Kendall Rank test method is used to test and analyze the runoff variation trend of the liusha River basin under control. The variation trend of annual runoff sequence is shown in Figure 3.

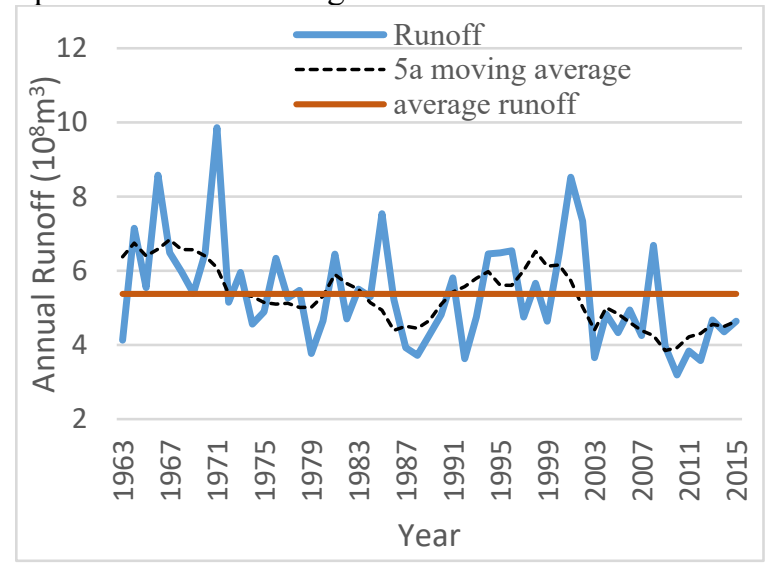

Fig.3.Annual runoff variation trend chart of Liusha River

From 1963 to 2015, the average runoff of Liusha River basin was $5.38 \times 10^{8} \mathrm{~m}^{3}$. The highest value was $9.86 \times 10^{8} \mathrm{~m}^{3}$, which appeared in 1971 and was $4.58 \times 10^{8} \mathrm{~m}^{3}(87 \%)$ higher than the average runoff of many years. The second highest value was $8.52 \times 10^{8} \mathrm{~m}^{3}$, which appeared in 2001. The lowest value was $2.89 \times 10^{8} \mathrm{~m}^{3}$, which appeared in 1962 . It was lower than the multi-year average runoff of $2.39 \times 10^{8} \mathrm{~m}^{3}(45 \%)$. It can be seen from figure 2 that the annual runoff shows a slow rise and decline trend of change after tested menghai station Kendall rank correlation test statistics $|\mathrm{U}|=2.78>1.96$, indicating that the runoff of Liusha river had a significant variation trend and a significant reduction trend between 1963 and 2015 .

\subsection{Analysis of turning points by cumulative anomaly method}

According to the sequence analysis of runoff, rainfall and evaporation cumulative anomaly values, the change curves of runoff, rainfall and evaporation cumulative anomaly values of Liusha river were obtained, as shown in Figure 4.

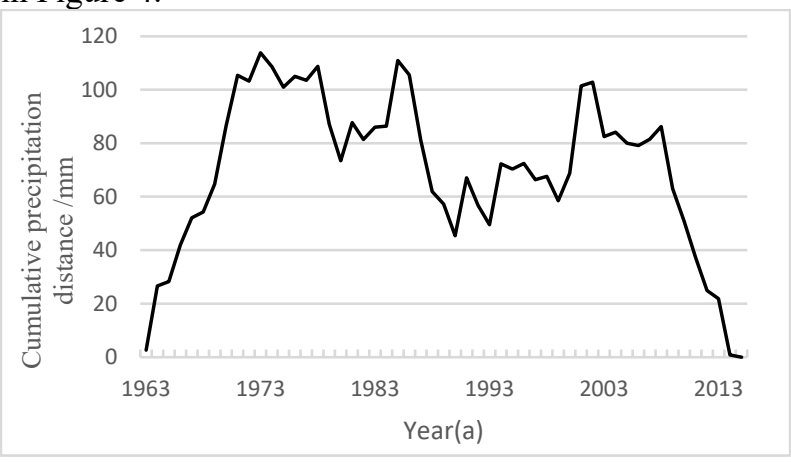

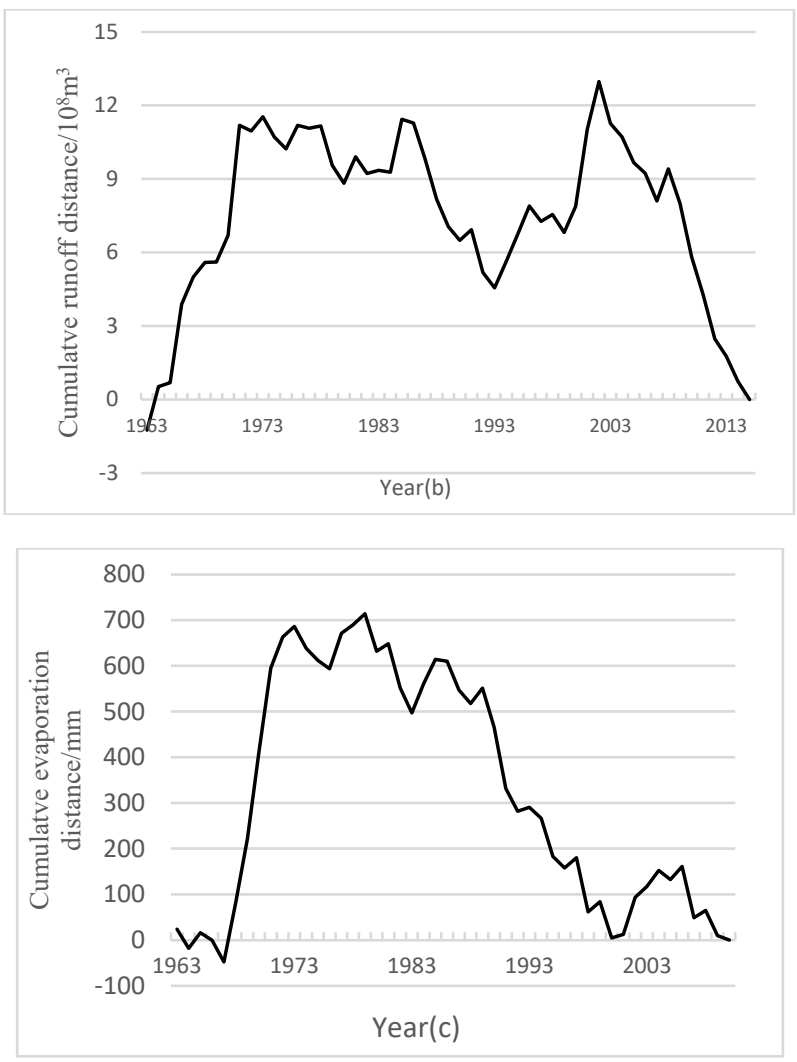

Fig.4(a) (b) (c) The cumulative anomaly change process of runoff, rainfall and evaporation

Before 1979, the evaporation showed a trend of continuous increase. After 1979, after a few years of continuous decrease, the evaporation showed a changing trend of first increase and then decrease around 1983. Through analysis and comparison, it can be seen that the evaporation capacity of Liusha River turned around in 1979 and 1983 respectively.The precipitation and runoff in that period showed the same trend at 2003, which first increased and then decreased. Therefore, it can be considered that 2003 was the first year in which cumulative changes in rainfall and runoff occur. When there was an inflection point of evaporation anomaly in 1979, there was no inflection point of runoff accumulation anomaly, indicating that evaporation had no significant influence on runoff during this period. However, the turning point of rainfall and runoff change was synchronous.It is indicated that runoff was significantly affected by rainfall.

\section{Conclusion}

Between 1963 and 2015, the runoff of Menghai Hydrological Station of Liusha River showed a downward trend.The runoff of Liusha River has abrupt change in 2003 and then decreased significantly. As a result of population pressure and economic development, a large number of rubber and tea trees were planted in the Liusha River Basin. It leads to the logging of a large number of primary tropical and monsoon rainforests and the change of land use/vegetation cover. The high intensity of human activities means that climate change 
is not the only major factor causing the runoff change in the basin, and the main reason leading to the decrease of Liusha river runoff may be human activities.

\section{Acknowledgement}

We thank Yunnan Provincial Joint Fund (202001BA070001-243) provide financial support.

\section{Reference}

1. Ravichandran S. Hydrological influence on the water quality trends in Tamiraparani Basin, south India [J]. Environmental Monitoring and Assessment, 2003, 87(3): 293.

2. Wang Jinfeng. Analysis of runoff change in Beida River Basin under the influence of climate change and human activities [J].Resources and Environment in arid Regions, 2019, 33(03):86-91.

3. El-Hamid H T A, Caiyong W, Hafiz M A, et al. Effects of land use/land cover and climatic change on the ecosystem of North Ningxia, China[J]. Arabian Journal of Geosciences, 2020, 13(20):1-13.

4. ASA, BVNA, CDT, et al.Assessment of land use and climate change effects on land subsidence using a hydrological model and radar technique[J]. Journal of Hydrology, 2019, 578:124070-.

5. Wang Suiji, Yan Yunxia, YAN Ming, et al. Contribution rate analysis of Precipitation and human activities to runoff change in Huangfuchuan Basin: The Proposal and Application of a comparative method of cumulative slope Change Rate [J].Journal of Geography, 2012, 67(3): 388-397.

6. Li Dan, Xu Wen, YE Changqing, et al. Analysis on the characteristics of hydrological regime change in Wanquan River Basin under the influence of climate change and human activities [J].Hydropower Science, 2019(12). 